\title{
Partial Syndrome of Myotonic Dystrophy: Clinical Presentation and Follow-up
}

\author{
Jean Mathieu, Marcel Simard, Marc De Braekeleer, Camil Boily and Aurèle Deschênes
}

\begin{abstract}
The neurological and ophthalmological investigation of 602 members of 88 Saguenay kindreds affected by myotonic dystrophy (MyD) revealed 130 persons with a partial syndrome. These patients, whose average age was 34.1 years, showed different abnormalities such as particular ophthalmic and/or neuro-muscular signs, suggesting $\mathrm{MyD}$ in the absence of myotonia or typical lens abnormalities. After an average period of 2,4 years, 44 of these 130 patients were reassessed by the same neurologists and ophthalmologists. Thirty still had a partial syndrome, 8 showed a typical form of MyD and 6 no longer presented any identifiable anomaly. This preliminary follow-up study of the partial MyD syndrome did not allow us to identify any clinical anomaly from which the presence of the MyD gene could be predicted in a significant way. It furthermore suggested that the identification of equivocal or unspecific signs among these patients can sometimes lead to misdiagnosis. This must be taken into account when providing genetic counselling. It furthermore indicates that the use of DNA probes is essential for a reliable identification of asymptomatic MyD gene carriers.

RÉSUMÉ: Le syndrome partiel de la dystrophie myotonique: présentation et évolution clinique L'évaluation neurologique et ophthalmologique de 602 personnes issues de 88 familles saguenéennes touchées par la dystrophie myotonique (DM) a révélé la présence de 130 individus porteurs d'un syndrome partiel. Ces patients, âgés de 34,1 ans en moyenne, présentent différentes anomalies ophthalmiques et/ou neuromusculaires évocatrices de la DM, malgré l'absence de myotonie ou d'anomalies cristalliniennes typiques. Parmi ces 130 patients, 44 ont été réévalués, après un intervalle moyen de 2,4 ans, par la même équipe de neurologues et d'ophthalmologistes. Trente (30) présentaient encore un syndrome partiel, huit (8) une forme typique de la DM et six (6) individus n'avaient plus aucune anomalie identifiable. Cette étude préliminaire de l'évolution du syndrome partiel de la DM n'a pas permis de repérer de manifestations cliniques pouvant permettre de prédire de façon significative la présence du gène de la DM. Par ailleurs certains signes équivoques ou peu spécifiques présentés par ces patients peuvent parfois entraîner des erreurs diagnostiques. Cette éventualité doit faire l'objet de discussion lors de la consultation génétique offerte à ces patients et rend essentielle l'utilisation des techniques de linkage génétique pour l'identification fiable des porteurs asymptomatiques du gène de la DM.
\end{abstract}

Can.J. Neurol. Sci. 1989: 16:99-103

The Saguenay-Lac-Saint-Jean (SLSJ) region (population $300,000)$ is a rather isolated area located 125 miles north-east of Quebec City. The prevalence of myotonic dystrophy (MyD) is very high in this area; in 1987, 1 in 510 inhabitants was affected $(196 / 100,000)$. During the clinical investigation of kindreds affected with MyD, we examined several family members who presented anomalies suggesting $\mathrm{MyD}$ but for whom the diagnosis could not be confirmed. Other familial studies also reported similar cases referred to as "forme fruste", 1 doubtful case, ${ }^{2}$ equivocal case, ${ }^{3}$ case with suspended diagnosis ${ }^{4}$ or partial syndrome. ${ }^{5}$ None of these studies dealt with the follow-up of these patients.

In this paper, the clinical characteristics of SLSJ patients with a partial syndrome are presented, together with a preliminary study on the course of clinical signs for some of them.
These observations should improve our knowledge of the initial stage of MyD and assess the discriminating capacity of our diagnostic tools.

\section{Materials and Methods}

From 1976 to 1982, field screening allowed the recognition of 369 cases presumed to be affected by MyD in the SLSJ region. ${ }^{6} \mathrm{~A}$ number of these cases, as well as other symptomatic or asymptomatic family members, were examined at the Muscular Dystrophy Clinic of the Chicoutimi Hospital between September 1981 and December 1985. All were independently examined by a neurologist (JM, CB) and an ophthalmologist (MS, AD).

The neurological assessment included a complete neuromuscular examination and concentric needle electromyography

From the Division of Neurology, Hôpital de Chicoutimi (J.M., C.B.); Division of Ophtalmology, Hôpital de Chicoutimi (M.S., A.D.); SOREP, Université du Québec, Chicoutimi, Québec (M.D.B.)

Reprint requests to: Jean Mathieu, M.D., Hôpital de Chicoutimi, 305 St-Vallier, Chicoutimi, Québec, Canada G7H 5H6 
(DISA 1500). Generally, the EMG was performed on the abductor pollicis brevis muscle. When this electromyogram of the abductor pollicis brevis muscle showed non-conclusive anomalies, the EMG was then completed by analysing other distal, proximal or facial muscles.

The ocular examination included the measurement of the intra-ocular tension with a Goldman tonometer and a study of the lens with a Haag-Streit type slit-lamp following pupilary dilatation with a $1 \%$ tropicamide- $1 \%$ cyclopentolate solution.

Patients were then classified as normal, affected or carrier of a partial syndrome according to the results obtained. The clinical signs typical of MyD were well described by Walton ${ }^{7}$ and Harper. ${ }^{8}$ The essential criteria used to make a diagnosis of $\mathrm{MyD}$ were the presence of non-equivocal myotonia (clinical or electromyographic) or non-equivocal colored opacities detected by slit-lamp examination. A partial syndrome diagnosis was made when a person presented neuro-muscular (clinical or electromyographic) and/or ophthalmic signs suggestive of MyD but not the essential diagnostic criteria mentioned above.

Forty-four patients with a partial syndrome were re-examined by the same medical team, using the same protocol, after a mean interval of 2.4 years ( 2 to 6 years). This relatively short time interval was based upon requests of several patients wishing to carry out family planning without unreasonable delays.

An effort was made to determine the types of anomalies which were statistically predictive of the evolution of the partial syndrome. Since the number of patients reexamined was too low to estimate the chi-square $\left(\mathrm{X}^{2}\right)$, we used a randomization test, the random data permutation test ${ }^{9}$ which determines the significance of experimental results by permuting the data and calculating t repeatedly.

\section{ReSUlts}

From September 1981 to December 1985, 690 individuals belonging to 88 kindreds affected with MyD were assessed at the Muscular Dystrophy Clinic of the Chicoutimi Hospital. Besides the 88 probands, 324 individuals were diagnosed as affected with MyD. We identified 130 carriers of a partial syndrome and 148 individuals were classified as normal. Several members of these 88 kindreds have not yet been examined. Clinical data of the 130 carriers of a partial syndrome are presented in this report.

\section{Initial Assessment of Carriers of a Partial Syndrome $(\mathrm{N}=130)$}

\section{Age/Sex Profile}

Figure 1 shows the age/sex distribution of the population carrying a partial syndrome. An uneven distribution of sexes ( 57 men, 73 women) was observed although MyD affects both sexes (equally). This difference may reflect a higher health care consumption among women.

A partial syndrome was diagnosed in patients from 5 to 81 years old. The mean age at the time of diagnosis was 34.1 years.

\section{Family History}

The 130 carriers of a partial syndrome were distributed in 49 families. All had at least one affected relative. According to the relationship with the closest affected kin, $89.3 \%$ of the patients ran a 25 to $50 \%$ risk of being affected and the others $(10.7 \%)$ a
12.5 or $6.25 \%$ risk. The transmission was paternal in 35 patients, maternal in 53 patients and unknown in the remaining 42 patients.

\section{Clinical Anomalies}

Each patient carrier of a partial syndrome displayed one or several neurologic, electromyographic and/or ophthalmic anomalies (Table 1). The neurologic abnormalities most frequently noted were temporal wasting $(29 \%)$, slight weakness or wasting of the sterno-mastoids (20\%), slight weakness of the digit flexors or of the wrist extensors $(13 \%)$ and hypo-areflexia $(13 \%)$, particularly in the upper limbs.

A high frequency $(37 \%)$ of muscular irritability was noted during electromyography. Pseudomyotonic discharges at inser-

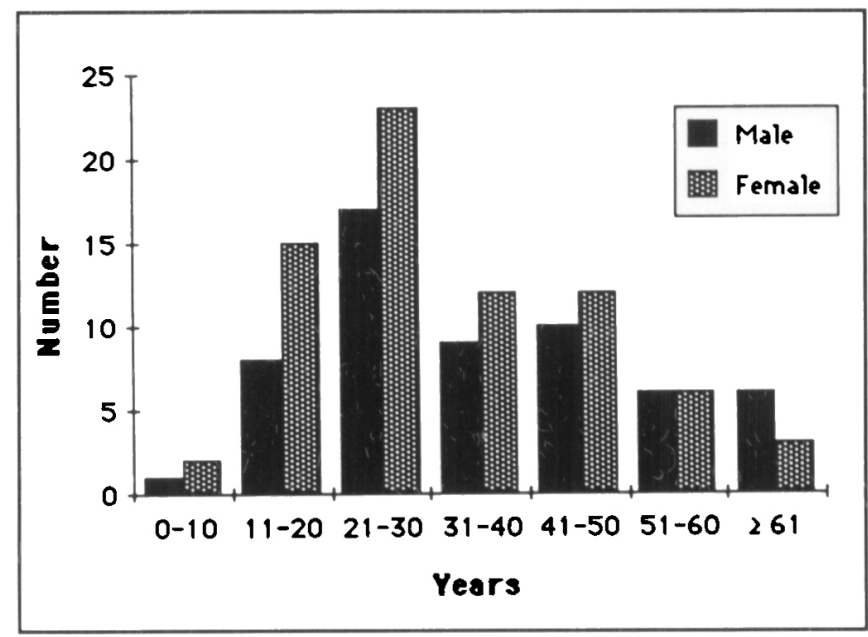

Figure I - Partial syndrome: age/sex distribution $(N=130)$

Table 1: Clinical Features of Patients with Partial Syndrome ( $N=130$ Patients)

\begin{tabular}{lrr}
\hline & \multicolumn{2}{c}{ Patients } \\
& Number & $(\%)$ \\
\hline Neurologic signs & & \\
Temporal wasting & 38 & $(29)$ \\
Jaw muscles wasting & 8 & $(6)$ \\
Slight facial weakness & 9 & $(7)$ \\
Slight ptosis & 15 & $(12)$ \\
Slight nasal speech & 4 & $(3)$ \\
Mild sternomastoids wasting/weakness & 26 & $(20)$ \\
Mild distal weakness of the limbs & 17 & $(13)$ \\
$\quad$ Deep tendons hypo/areflexia & 17 & $(13)$ \\
$\quad$ Equivocal myotonia & 8 & $(6)$ \\
Electromyographic signs & & \\
Increased insertion activity & 49 & $(37)$ \\
Pseudo-myotonic discharges & 22 & $(17)$ \\
Mild active denervation signs & 3 & $(2)$ \\
$\quad$ Equivocal myotonic discharges & 7 & $(5)$ \\
Ophthalmic signs & & \\
A) Slit-lamp changes & & \\
Whitish opacities & 33 & $(25)$ \\
Dust-like whitish opacities & 57 & $(44)$ \\
Equivocal iridescent opacities & 33 & $(25)$ \\
Mild posterior subcapsular plaques & 49 & $(38)$ \\
B) Other abnormalities & & \\
Low intraocular tension ( $\leq 10$ mm Hg) & 3 & $(2)$ \\
& &
\end{tabular}


tion or on displacement of the needle were also observed (17\%). Some electromyographic recordings $(5 \%)$ displayed rare myotonic discharges; however these were too infrequent to allow a diagnosis of $\mathrm{MyD}$.

The ophthalmic abnormalities were the most common. We observed dust-like whitish opacities in $44 \%$, slight sub-capsular plaques in $38 \%$ and whitish opacities in $25 \%$ of the patients. A few iridescent colored opacities, not sufficient to suggest a MyD diagnosis, were observed in 33 patients (25\%).

Some carriers of a partial syndrome had only one type of anomaly (neurologic, electromyographic, or ophthalmic), while others presented an association of several of them. Table 2 presents the distribution of patients according to these criteria. Fifty-seven patients showed ophthalmic signs alone while another 57 presented these in association with other types of anomalies. Associations of two or even three anomalies were observed for sixty-five (50\%) of the patients.

\section{Follow-up Assessment of Partial Syndromes $(\mathbf{N}=\mathbf{4 4})$}

Forty-four patients with a partial syndrome were reexamined after a mean period of 2.4 years ( 2 to 6 year interval). Following this second assessment, 30 patients were still classified as carriers of a partial syndrome, 8 were found to be affected and 6 were declared normal because they no longer displayed the anomalies noted at the initial assessment. The sex distribution of these patients was the same in all three groups. There was no significant difference between the mean age of patients affected with $\mathrm{MyD}(35.1 \pm 14.9$ years), patients with a partial syndrome $(29.3 \pm 10.8$ years) and normal individuals $(32.8 \pm 11.1$ years). The mean interval between the first and the follow-up assessments was significantly longer for the affected patients (3.0 \pm 1.9 years) than for the carriers of a partial syndrome ( $2.1 \pm 0.9$ years) or the normal individuals $(2.5 \pm 0.8$ years $)$ (Student t-test; $p=0.008$ ).

Among the six individuals declared normal after the followup assessment, 4 had only ophthalmic anomalies and 2 only neurologic abnormalities at the time of the first assessment. Among the 8 patients who turned out to be affected after the follow-up assessment, 5 had ophthalmic anomalies alone, l.

Table 2: Partial Syndrome: Distribution of Cases According to Types of Anomalies

\begin{tabular}{|c|c|c|}
\hline & \multicolumn{2}{|c|}{ Patients } \\
\hline & Number & $(\%)$ \\
\hline One type of anomalies & 65 & $(50)$ \\
\hline Ophthalmic & 57 & (44) \\
\hline Neurologic & 5 & (4) \\
\hline Electromyographic & 3 & ( 2 ) \\
\hline Two types of anomalies & 35 & $(27)$ \\
\hline Ophthalmic and neurologic & 17 & (13) \\
\hline Ophthalmic and electromyographic & 10 & ( 8 ) \\
\hline Neurologic and electromyographic & 8 & ( 6 ) \\
\hline Three types of anomalies & 30 & (23) \\
\hline \multicolumn{3}{|l|}{$\begin{array}{l}\text { Ophthalmic, neurologic } \\
\text { and electromyographic }\end{array}$} \\
\hline Total & 130 & $(100)$ \\
\hline
\end{tabular}

ophthalmic and neurologic abnormalities and 2 ophthalmic, neurologic and electromyographic anomalies at the first assessment.

We tried to consider whether an anomaly or a group of anomalies noted during the initial assessment could have a predictive value for the presence of the MyD gene as evaluated by an unequivocal manifestation of the disease. The statistical analysis was performed on the 44 patients who were reexamined. The randomization test did not reveal any relationship between the diagnosis of MyD at the follow-up assessment and an anomaly, a type of anomaly or an association of types of abnormalities noted during the first assessment $(p=0.069)$.

\section{Some Clinical Observations}

Patient 1. A 23 year old woman had a brother and a sister affected with MyD. In 1981, a diagnosis of partial syndrome was made because of the presence of white opacities and equivocal colored opacities on slit-lamp examination. The neurologic and electromyographic examinations were normal. In 1984, the follow-up assessment revealed temporal wasting, weakness of the facial muscles and myotonic discharges on electromyography, confirming the diagnosis of MyD.

Patient 2. A 56 year old man had four children and a sister affected with MyD. In 1983, a diagnosis of partial syndrome was made because of the presence of doubtful colored opacities despite normal neurologic and electromyographic examinations. In 1985, the diagnosis of MyD was confirmed by the presence of non-equivocal colored opacities and of myotonic discharges on electromyography.

Patient 3. A 35 year old woman had several uncles affected with MyD. The 1983 assessment showed slight temporal wasting, discrete weakness of the sterno-mastoids and of the digit flexors, areflexia of the upper limbs, irritability and a few pseudomyotonic discharges on electromyography and discrete subcapsular plaques on slit-lamp examination. A diagnosis of partial syndrome was then made. In 1985, the diagnosis of MyD was confirmed by the presence of typical myotonic discharges in the electromyogram and of colored opacities on slit-lamp examination. The neurologic signs remained unchanged.

Patient 4. A 45 year old man had a brother affected with MyD. The 1983 assessment showed whitish opacities and some sub-capsular plaques allowing a diagnosis of partial syndrome. The neurologic and electromyographic examinations were normal. In 1985, the slit-lamp examination did not reveal any significant anomaly and the neuro-electromyographic assessment remained normal. The subject was considered normal.

\section{DisCuSSION}

The wide variability of the phenotypic expression of MyD is well known. Several affected individuals show a typical phenotype: weakness of facial and cervical muscles; weakness of distal limb muscles slowly progressing to proximal muscles, with myotonia; cataracts; baldness; cardiac involvement and other systemic manifestations. Others suffer from a more severe form of the disorder, called the congenital form, with major muscle involvement present at birth and mental retardation. At the other end of the spectrum, some patients present lens manifestations alone, sometimes at an advanced age. 
Throughout familial screenings, it is therefore not surprising to find some individuals who display, at variable ages, slight or equivocal signs of the disorder which makes the diagnosis quite difficult. Some authors have also reported patients showing such equivocal signs or a partial syndrome (Table 3 ). The proportion of such cases observed in the Saguenay population is $21.5 \%$ while that reported by others range from $10.4 \%$ to $20.3 \%$. These studies, however, can hardly be compared with one another because the populations that were screened were sampled differently. Pryse-Phillips et $\mathrm{al}^{5}$ looked at an entire family, Bundey and Carter $^{3}$ at first degree relatives and Harper ${ }^{2}$ at asymptomatic first degree relatives. In the SLSJ region, the ascertainment of MyD cases has not been completed. Our data also differ from the others by the large size of population tested in our study as reflected by the extremely high prevalence of MyD in this area.

In our population sample, the partial syndrome is mainly characterized by the presence of lens anomalies (whitish or dust-like whitish opacities, doubtful colored opacities, discrete sub-capsular plaques) and of neuromuscular abnormalities such as muscle irritability, on electromyography, and temporal wasting. These clinical signs are slightly different from those observed by Pryse-Phyllips et $\mathrm{a}^{5}$ in Labrador (Newfoundland) who found a higher proportion of patients showing facial weakness and ocular hypotonia.

The follow-up assessment done after a mean period of two years showed that, in 30 of the 44 patients reexamined $(68 \%)$, the time interval was too short to allow recognition of significant clinical changes. A five-year interval would have been more appropriate but seemed less suitable for a large number of patients in view of familial planning. The follow-up assessment showed that 8 patients presented the MyD typical phenotype on the second examination. This observation allows us to predict, like Pryse-Phillips et al, ${ }^{5}$ that some individuals with a partial syndrome are indeed carriers of the MyD gene. Moreover, according to our results (unpublished data), 44 affected children were born from 15 patients with a partial syndrome, identifying these parents as obligate carriers of the MyD gene.

However, our observations indicate that the presence of slight or equivocal signs may lead to overdiagnosis. Indeed, 6 patients, who were diagnosed as partial syndromes following the initial assessment, were classified as normal after the follow-up examination. Therefore, the lack of discrimination of the diagnostic tools need to be discussed during genetic counselling of these patients.

The statistical analysis of the types of anomalies noted during the initial assessment of patients whose diagnosis was modi- fied following the second examination could not identify signs that had a predictive value of this course. Nevertheless, one can think that the risk for an individual of being affected with $\mathrm{MyD}$ is a function of the number of anomalies or of types of anomalies observed. Sixty-five patients displayed an association of two, or even three, types of anomalies; this observation could mean that these individuals have a higher risk of being carriers of the MyD gene than the patients who show only one type of anomaly. Therefore, it is obvious that the neurologic examination must be complimented by electromyography and slit-lamp examination to better identify the heterozygotes.

Patients with a partial syndrome are asymptomatic and the anomalies noted probably represent an initial stage of the ocular or neuromuscular involvement several months or years before the appearance of more characteristic signs and symptoms of MyD. This is particularly true in young patients, since the typical manifestations of the disease usually appear between age 20 and 40. As for older patients, the presence of a partial syndrome probably accounts for some of the reduced penetrance of MyD. The observations made so far do not allow us to think that the partial syndrome is a genetically different disorder than the typical MyD.

The low discriminating capacity of the clinical diagnostic tests for MyD makes the use of recombinant DNA techniques and genetic linkage analysis $10,11,12$ essential for a reliable identification of the carriers of the MyD gene. Using a sample of the Saguenay families affected with MyD, the molecular genetic unit of the Laval University Hospital (Quebec City), in collaboration with other research centers, is working on the identification and the validation of DNA probes. ${ }^{10}$ In the near future, these new diagnostic tools will be used primarily to ensure a reliable diagnosis of the patients with a partial syndrome.

The use of molecular biology techniques will also lead to the identification of carriers of the MyD gene several years before the occurrence of the clinical signs or symptoms. These individuals will be entitled to receive an appropriate prognostic estimation. The long clinical follow-up of the patients with a partial syndrome will lead to a better knowledge of the natural history of this disorder and will improve our prognostic expertise.

\section{ACKNOWLEDGEMENTS}

The authors thank Dr. Robert Côté, Mr. Michel Perron, Mrs. Claude Prévost and Mrs. Suzanne Veillette for their valuable collaboration in the revision of the manuscript. This research was supported, in part, by a grant from the "Programme d'Aide Institutionnelle à la Recherche" (JM, MDB)

Table 3: Patients with Incomplete Manifestations or "Partial Syndrome": Data from Previous MyD Heterozygotes Screening Reports

\begin{tabular}{|c|c|c|c|c|c|}
\hline \multirow[t]{2}{*}{ Authors } & \multirow{2}{*}{$\begin{array}{c}\text { Probands } \\
\qquad \mathbf{N}^{*}\end{array}$} & \multirow{2}{*}{$\begin{array}{c}\text { Relatives } \\
\mathbf{N}\end{array}$} & \multirow{2}{*}{$\begin{array}{c}\text { Affected } \\
\qquad \mathbf{N}\end{array}$} & \multicolumn{2}{|c|}{ Partial Syndrome } \\
\hline & & & & $\mathbf{N}$ & $(\%)$ \\
\hline Bundey and Carter $(1970)^{3}$ & 38 & 124 & 34 & 13 & $(10.4)$ \\
\hline Polgar et al $(1972)^{4}$ & 12 & 44 & 21 & 9 & $(20.4)$ \\
\hline Harper $(1973)^{2}$ & 47 & 131 & 23 & 18 & $(13.7)$ \\
\hline $\operatorname{Marcoz}(1978)$ & 4 & 120 & 24 & 14 & $(11.6)$ \\
\hline Pryse-Phillips et al $(1982)^{5}$ & & 133 & 32 & 27 & $(30.3)$ \\
\hline Present study & 88 & 602 & 324 & 130 & $(21.5)$ \\
\hline
\end{tabular}

*Number of individuals 


\section{REFERENCES}

1. Marcoz JP. Dépistage des hétérozygotes dans une grande famille atteinte de maladie de Steinert aux manifestations cliniques variées. J Génét Hum 1978; 3: 237-274

2. Harper PS. Pre-symptomatic detection and genetic counselling in myotonic dystrophy. Clin Genet 1973; 4: 134-140.

3. Bundey S, Carter CO. Early recognition of heterozygotes for the gene for dystrophia myotonica. J Neurol Neurosurg Psychiatry 1970; 33: 279-293.

4. Polgar JG, Baradley WG, Upton ARM, et al. The early detection of dystrophia myotonica. Brain 1972; 95: 761-776.

5. Pryse-Phillips W, Johnson GJ, Larsen B. Incomplete manifestations of myotonic dystrophy in a large kinship in Labrador. Ann Neurol 1982; 11: 582-591.

6. Veillette S, Perron M, Desbiens F. La dystrophie myotonique: étude épidémiologique et socio-géographique au Saguenay-Lac-
Saint-Jean. Rapport de recherche, Jonquière: CEGEP de Jonquière 1986

7. Walton J. Disorders of voluntary muscle. New York: Churchill Livingstone 1981: 510-514.

8. Harper PS. Myotonic dystrophy. Philadelphia: W.B. Saunders 1979: 14-30.

9. Edginton ES. Randomization tests. New York: M. Dekker Inc. 1980.

10. Laberge C, Gaudet D, Morissette J, et al. Linkage of myotonic dystrophy and apoE in a French Canadian isolate. Cytogenet Cell Genet 1985; 40: 675 .

11. Shaw DJ, Meredith AL, Sarfarazi M, et al. The apolipoprotein CII gene: Subchromosomal localisation and linkage to the myotonic dystrophy locus. Hum Genet 1985; 70: 271-273.

12. Roses A.D., Yamaoka L.H., Pericak-Vance M.A, et al. A new DNA probe tightly linked to myotonic muscular dystrophy (Abstract). Ann Neurol 1986; 20: 137. 